\title{
Is there a link between inflammation and fatigue in multiple sclerosis?
}

\author{
Moussa A Chalah',2 \\ Samar S Ayache ${ }^{1-3}$
}

'EA 439I, Excitabilité Nerveuse et Thérapeutique, Université ParisEst-Créteil, Créteil, France; ${ }^{2}$ Service de Physiologie - Explorations Fonctionnelles, Hôpital Henri Mondor, Assistance Publique - Hôpitaux de Paris, Créteil, France; ${ }^{3}$ Neurology Division, Lebanese American University Medical Center, Rizk Hospital, Beirut, Lebanon
Correspondence: Moussa A Chalah Service de Physiologie - Explorations Fonctionnelles, Hôpital Henri Mondor, 5I Avenue de Lattre de Tassigny, Créteil 94010 , France

$\mathrm{Tel}+33$ | 498| 2694

Fax +33 | 498| 4660

Email moussachalah@gmail.com
This article was published in the following Dove Press journal: Journal of Inflammation Research

\begin{abstract}
Purpose: Among autoimmune diseases of the central nervous system stands multiple sclerosis (MS), which is characterized by demyelination, synaptopathy, and neurodegeneration. MS fatigue can affect up to $90 \%$ of patients and be very disabling, with a drastic impact on their quality of life. To date, the evaluation of MS fatigue has relied mainly on subjective scales, and actual therapeutic interventions are challenged by modest efficacy and numerous undesirable effects. Therefore, finding biomarkers of MS fatigue might help in optimizing evaluation and treatment strategies. The main objective here was to assess the relationship between MS fatigue and inflammatory or other immunomediated markers.

Methods: Research was conducted according to PRISMA guidelines. Computerized databases (ie, PubMed/Medline and Scopus) were consulted till February 2018 aiming to identify articles that addressed inflammation and MS fatigue. Studies in English and French published at any time were considered.
\end{abstract}

Results: A total of 27 studies matched the research criteria. Inconsistency existed regarding the relationship between fatigue and the orexin A system, hypothalamus-pituitary-adrenal axis, and cerebrospinal fluid inflammatory markers. As for peripheral markers, although there was scarcity in the available data, serum proinflammatory cytokines (ie, IL6, TNF $\alpha$, and IFN $\gamma$ ) seem to be associated with MS fatigue. Finally, no link was found between MS fatigue and T-cell populations (ie, $\mathrm{CD}^{+}{ }^{+} \mathrm{CD} 4{ }^{+} \mathrm{T}$ lymphocytes, regulatory $\mathrm{T}$ cells) or other peripheral markers of inflammation (ie, CRP, erythrocyte-sedimentation rate, soluble ICAM1).

Conclusion: Future large-scale studies would benefit from comparing the relationship between fatigue and immune measures in patients with different disease phenotypes with and without disease-modifying drugs. With the subjective nature of fatigue scales, finding objective biomarkers for fatigue would be of great help.

Keywords: pathophysiology, cytokines, interleukins, cerebrospinal fluids, inflammatory markers

\section{Introduction}

Among autoimmune diseases of the central nervous system (CNS) stands multiple sclerosis (MS), which is the second-most common cause of physical handicap in young individuals. ${ }^{1-3}$ Its pathophysiological hallmarks are demyelination, synaptopathy, and neurodegeneration. ${ }^{4,5}$ Throughout the disease course, MS patients can experience periods of acute symptom emergence separated by symptom-free intervals. This characterizes the relapsing-remitting (RR) MS phenotype, which usually converts to a secondary progressive phase where patients can experience steady clinical deterioration. ${ }^{3}$ Primary progressive MS represents a third disease phenotype, where patients 
witness an evolutionary pattern of their disease from onset. Demyelination appears to be the fingerprint of the first type (ie, RRMS), whereas neurodegeneration/axonal loss seems to be the backbone of progressive types. ${ }^{5}$ While an immunomediated attack by blood-borne autoreactive $\mathrm{T}$ lymphocytes would dictate the occurrence of demyelination, immunomediated processes involving immune cells and soluble cytokines could also lead to excitotoxic changes and neurodegeneration, based on experiments involving the animal model of MS. ${ }^{5}$

Regardless of the disease phenotype, patients may experience a panel of symptoms involving the sensory, motor, cerebellar, emotional, cognitive, and behavioral domains. Among the frequently encountered symptoms, MS fatigue can affect up to $90 \%$ of patients and be very disabling, with a drastic impact on their quality of life. ${ }^{6}$ It is a challenging symptom that is described by patients as "malaise", "excessive tiredness", or "weakness" that seems to worsen throughout the day, as well as with hot and humid environments. ${ }^{4}$ From a scientific perspective, MS fatigue is considered a multidimensional symptom with physical, cognitive, and psychosocial components. Among the available definitions, some authors consider fatigue a lack of physical and/or mental energy. ${ }^{4,6}$ For another group of authors, fatigue designates a failure to initiate and/or maintain physical or mental activities requiring self-motivation in the absence of or not related to physical or cognitive dysfunction. ${ }^{4,6}$

Ever since the original work of Freal et al in 1984, ${ }^{7}$ there has been growing interest in understanding the pathophysiology of MS fatigue, especially the fact that this symptom remains difficult to be reported by patients and managed by physicians. To date, the evaluation of MS fatigue has relied mainly on subjective scales, such as the Modified Fatigue Impact Scale (MFIS), Fatigue Severity Scale (FSS), and Fatigue Scale for Motor and Cognitive Functions (FSMC), among others, and actual therapeutic interventions are challenged by their modest efficacy in face of their numerous undesirable effects. ${ }^{6}$ From this perspective, understanding the underlying mechanisms of this symptom might be of help in easing its evaluation and optimizing patient care. In a previous work, we addressed the cerebral anatomical correlates of MS fatigue. ${ }^{4}$ Based on neuroimaging studies, pathological findings were observed in a corticostriatothalamocortical loop that was linked to MS fatigue. These findings included regional gray- and white-matter pathologies, as well as abnormal patterns of brain activation. The inflammatory and immune medium might be implicated as well in the context of MS fatigue. Therefore, the main aim of the current work was to assess the role of MS-related central and peripheral inflammation and immunomediated endocrine dysregulation in the development of this symptom.

\section{Study selection}

Research was conducted according to the PRISMA guidelines. ${ }^{8}$ First, computerized databases that index peer-reviewed journals (PubMed/Medline and Scopus) were consulted till the end of February 2018. The research aimed to identify articles that addressed the relationship between MS fatigue and inflammatory, immune, and endocrine factors. Studies that were published at any time in English and French were considered. The following research terms were combined: ("fatigue" OR "fatigue severity scale" OR "FSS" OR "Modified Fatigue Impact Scale" OR "MFIS" or "Fatigue Scale for Motor and Cognitive Functions" or "FSMC") AND ("multiple sclerosis" OR "MS") AND ("inflammation" OR “inflammatory" OR “immune" OR “cytokine” OR "interleukin" OR “cerebrospinal fluid" OR "CSF” OR "lymphocytes" OR "blood cells" OR "endocrine"). In addition, both coauthors independently checked the references of the articles obtained, aiming to obtain additional sources. The initial search identified 503 articles in PubMed/Medline and 258 articles in Scopus. After removal of duplicates and excluding reviews, opinions, editorials, commentaries, viewpoints, and research articles involving healthy volunteers or patients with autoimmune diseases other than MS, 25 articles were retained. An additional two references were retrieved from the articles' reference lists, yielding a total of 27 articles that were considered in the qualitative synthesis. These comprised information on MS fatigue and inflammatory or neuroendocrine markers and addressed the relationship between fatigue and hypothalamic function (two about the orexin A system, eight about the hypothalamic-pituitaryadrenal [HPA] axis), cerebrospinal fluid (CSF) markers (one about humoral and cellular CSF markers, one about CSF cytokines), serum-cytokine or blood-cell expression (15), or other peripheral inflammatory markers (three). In addition, six studies assessed changes in fatigue and cytokine profiles following exercise (four) or pharmacological (two) interventions. For the sake of this work, data of the selected studies are classified as central inflammation and neuroendocrine dysregulation and peripheral inflammation.

\section{Central inflammation, neuroendocrine dysregulation, and MS fatigue}

The exploration of inflammatory patterns within the CNS is possible by means of CSF analysis. However, the procedure 
consists of performing lumbar puncture, a procedure that is not only difficult to perform but also traumatizing for patients. This explains the scarcity of existing literature in this field. Available works on CSF analysis and MS fatigue focused on studying inflammation-related neuroendocrine dysregulation, humoral and cellular components, and cytokine levels. The remaining literature employed serum and salivary hormonal tests to assess specific hypothalamic functions and their relationship with fatigue.

To start, the hypothalamus plays a role in controlling several homeostatic functions. Some researchers were interested in assessing the relationship between MS fatigue and CSF levels of orexin A (also known as hypocretin 1), a hypothalamic peptide involved in arousal, motivation, energy, and circadian rythm. ${ }^{9}$ In fact, consolidating night sleep and keeping adequate daytime activity seem to be respectively promoted by low and high orexin A levels. ${ }^{10}$ Therefore, the rationale behind these works lay in the fact that neuroinflammation, such as that seen in MS, may impact the orexin $\mathrm{A}$ system. ${ }^{11}$ As such, one can speculate that downregulation of the latter system might happen in the course of MS and result in sleep disorders and/or fatigue. The first insight on orexin A-system status in MS derived from case reports on patients suffering from hypersomnia displaying low CSF levels of orexin A. ${ }^{12,13}$ Afterward, Papuć et al studied orexin A levels in MS patients and healthy controls. ${ }^{14}$ In the absence of group difference (MS vs healthy controls) with regard to this peptide, significant positive correlation was found between fatigue severity and orexin A levels in the whole patient group. Although this positive relationship was unexpected, the authors of this work hypothesized that this might have occurred due to the activation of endogenous compensatory mechanisms. One year later, Constantinescu et al were not able to replicate this correlation. ${ }^{15}$ Here, the authors found neither a group difference in orexin A levels between MS patients and other patients with inflammatory and noninflammatory neurological disease nor a correlation between orexin A levels and fatigue scores. Given the impact of daytime and season on orexin A levels, ${ }^{16}$ there is a good chance that these two studies were performed in different seasons and/or at different times of the day, a finding that could provide an explanation for the difference in the reported results.

Besides regulating the orexin A system, the hypothalamus is involved in many axes, of which the most studied is the HPA axis. Facing physiological and stressful situations, the hypothalamus secretes the corticotropin-releasing hormone (CRH) to stimulate the activity of the anterior pituitary gland. The latter responds by producing the adrenocorticotropic hormone $(\mathrm{ACTH})$ which in turn activates the adrenal glands (ie, zona fasciculata) yielding cortisol production. Proinflammatory cytokines can influence the activity of the HPA axis. ${ }^{17}$ This might provide an explanation for the HPA-axis dysregulation that appears to occur in patients with MS. ${ }^{18-23}$ In fact, the majority of studies on this topic have shown a hyperactive HPA axis, with fewer reports suggesting a hypoactivity pattern. Few studies have assessed the relationship between MS fatigue and HPA-axis activity.

Heesen et al employed combined dexamethasone-CRH challenge ${ }^{24-26}$ and low-dose dexamethasone-suppression tests. ${ }^{27}$ Both of these are used widely to measure activity of the HPA axis. The dexamethasone-suppression test consists of orally administering dexamethasone, a synthetic glucocorticoid, the night before blood sampling, in order to check the suppression of cortisol production (which is the normal physiological reaction). The combined dexamethasone-CRH-challenge test resembles the first, but $\mathrm{CRH}$ is also given intravenously the day of blood sampling and blood withdrawn at regular intervals to determine plasma levels of ACTH and cortisol levels at different times. In their four studies, the authors did not detect any significant association between MS fatigue and HPA-axis activity. ${ }^{24,25}$ In line with these results, Akcali et al employed a more comprehensive neuroendocrine evaluation that included plasma levels of $\mathrm{ACTH}$, cortisol, and other pituitary products, namely corticotropin-like intermediate-lobe peptide (CLIP), which is an ACTH variant, and melanocyte-stimulating hormone $(\alpha-\mathrm{MSH}, \beta-\mathrm{MSH}, \gamma-\mathrm{MSH})$, produced in the anterior pituitary gland $^{28}$ and previously found to be implicated in chronic fatigue syndrome (ie, $\alpha-\mathrm{MSH}){ }^{29}$ Although abnormal HPA measures were observed in MS patients compared to healthy controls (ie, higher ACTH, cortisol and $\alpha-\mathrm{MSH}$ and lower CLIP levels among patients), these measures did not differ between fatigued and unfatigued MS patients, suggesting the absence of any relationship between HPA-axis activity and MS fatigue. Conversely, a third study by Gottschalk et al employed combined dexamethasone-CRH-suppression tests and found significantly higher ACTH plasma levels among fatigued compared to unfatigued counterparts. ${ }^{30}$ The discrepancy in the results of the aforementioned works might have resulted from differences in clinical characteristics and treatments of the MS cohorts studied. Contrarily to Heesen et $\mathrm{al}^{24-27}$ and Akcali et al, ${ }^{28}$ who mostly enrolled patients receiving disease-modifying drugs, Gottschalk et al ${ }^{30}$ recruited drug-naïve patients. Here, it is worth noting that immunotherapy may impact cytokine-expression levels and thus might influence HPA-axis activity. ${ }^{31,32}$ 
In addition to the previously mentioned studies, Powell et al and Gold et al focused on the assessment of the cortisol awakening response (CAR) in MS patients, using a salivary test. ${ }^{27,33} \mathrm{CAR}$ is a spike in serum cortisol around 30-45 minutes after awakening, and is crucial for sustaining normal circadian rhythm and wakefulness. ${ }^{34}$ In the former trial, baseline fatigue scores, but not those obtained at the same day of CAR testing, were correlated with CAR. ${ }^{33}$ In the latter, CAR did not predict MS fatigue, as per regressionanalysis results. ${ }^{27}$

Among the other adrenal products stands dehydroepiandrosterone (DHEA) and its sulfated ester (DHEAS). Low DHEA and DHEAS levels have been linked to fatigue in some autoimmune diseases, such as systemic lupus erythematosus and rheumatoid arthritis..$^{35,36}$ In the only available study addressing serum levels of DHEA and DHEAS in MS patients, lower levels of both components were detected in fatigued compared to unfatigued patients. ${ }^{37}$ Interestingly, these results support those of an earlier pharmacological study, in which fatigue improvement was obtained following DHEA hormone replacement. ${ }^{38}$ However, the results of the latter work should be interpreted with caution, mainly because of its nonrandomized design. These preliminary findings warrant further research on this matter.

In addition to studies on HPA axis and MS fatigue, some researchers were interested in evaluating humoral, cellular, and other immune CSF markers. For instance, Biberacher et al included an exploratory and a validation phase that contained several evaluations. Of interest, they assessed the relationship between fatigue and several cellular and humoral CSF markers. ${ }^{39}$ No correlation was found between fatigue scores and any of the CSF markers. More interestingly, fatigue scores tended to correlate negatively with CSF CD4:CD8 ratio in the discovery group and correlate positively with the former ratio in the validation group. However, the multivariate model failed to detect associations between fatigue and CSF parameters in either group (exploratory vs validation). A recent work aimed to understand the relationship between MS-fatigue and CSF-interleukin levels, particularly IL6 and IL8. While IL6 took part in innate and adaptive immune responses, including differentiation of $\mathrm{T}$ helper 17 cells, IL8 was mainly implicated in innate immunoresponses and had cytokine- and chemokine-like functions. In this work, Brenner et al documented a significant correlation between fatigue scores and IL6 levels. ${ }^{40}$ This relationship was only seen among patients not receiving MS treatment. This might explain the absence of association in Biberacher et al, ${ }^{39}$ where $>75 \%$ of patients were under MS therapies. Another difference between the studies lies in their methodological approach which consisted of cellular and humoral markers in the first versus interleukins in the second. The different clinical and demographic characteristics between the cohorts might present a third plausible explanation for the inconsistency in their results. Table 1 provides a summary of these studies.

Table I Studies assessing the relationship between multiple sclerosis fatigue and central inflammatory or neuroendocrine markers

\begin{tabular}{|c|c|c|c|c|}
\hline Study & Population & $\begin{array}{l}\text { Fatigue } \\
\text { assessment }\end{array}$ & Measures & Results \\
\hline \multicolumn{5}{|c|}{ Studies assessing the HPA axis } \\
\hline Heesen et $\mathrm{a}^{24}$ & $\begin{array}{l}40 \text { patients (8 RR, I9 SP, I3 PP, sex } \\
\text { details NA, treated, but details NA); } \\
\text { I I HCs (sex-matched, details NA) }\end{array}$ & MFIS, FSS & Dex-CRH test & $\begin{array}{l}\text { HPA-axis hyperactivity among progressive } \\
\text { patients (but not RR patients) } \\
\text { No correlation between fatigue and HPA- } \\
\text { axis activity }\end{array}$ \\
\hline $\begin{array}{l}\text { Gottschalk } \\
\text { et a }\left.\right|^{30}\end{array}$ & $\begin{array}{l}\text { I5 fatigued MS patients (all RR, } \\
\text { I2F/3M); I } 6 \text { unfatigued MS patients (all } \\
\text { RR, IOF/6M); I9.4\% of whole cohort } \\
\text { treated }\end{array}$ & $\begin{array}{l}\text { FSS, MFIS, } \\
\text { VAS }\end{array}$ & Dex-CRH test & $\begin{array}{l}\text { Higher adrenocorticotropin (but not } \\
\text { cortisol) levels in the Dex-CRH test } \\
\text { among fatigued patients } \\
\text { Correlation analysis NA } \\
\text { No influence of sex on fatigue }\end{array}$ \\
\hline Heesen et $\mathrm{al}^{25}$ & $\begin{array}{l}\text { I5 fatigued MS patients ( } 6 \mathrm{RR}, 8 \\
\mathrm{SP}, \mathrm{I} \mathrm{PP}, 9 \mathrm{~F} / 6 \mathrm{M}, 66.7 \% \text { treated); I5 } \\
\text { unfatigued MS patients (II RR, } 2 \mathrm{SP}, 2 \\
\text { PP, sex-matched, } 9 \mathrm{~F} / 6 \mathrm{M}, 60 \% \text { treated) }\end{array}$ & MFIS, FSS & Dex-CRH test & $\begin{array}{l}\text { No group difference in Dex-CRH test } \\
\text { Correlation between fatigue and HPA-axis } \\
\text { activity }\end{array}$ \\
\hline Heesen et $\mathrm{al}^{26}$ & $\begin{array}{l}50 \mathrm{MS} \text { patients ( } 27 \mathrm{RR}, 23 \mathrm{SP} \\
29 \mathrm{~F} / 2 \mathrm{IM}, 48 \% \text { treated) }\end{array}$ & MFIS & Dex-CRH test & $\begin{array}{l}\text { Group comparison NA } \\
\text { No correlation between fatigue and HPA- } \\
\text { axis activity }\end{array}$ \\
\hline Gold et $\mathrm{al}^{27}$ & $\begin{array}{l}44 \mathrm{MS} \text { patients (all RR, all female, 59\% } \\
\text { treated) }\end{array}$ & MFIS, FSS & $\begin{array}{l}\text { Dexamethasone-suppression } \\
\text { test, salivary CAR test }\end{array}$ & $\begin{array}{l}\text { Group comparison NA } \\
\text { Dexamethasone-suppression test and } \\
\text { CAR data did not predict fatigue }\end{array}$ \\
\hline
\end{tabular}


Table I (Continued)

\begin{tabular}{|c|c|c|c|c|}
\hline Study & Population & $\begin{array}{l}\text { Fatigue } \\
\text { assessment }\end{array}$ & Measures & Results \\
\hline Powell et $\mathrm{a}^{33}$ & $\begin{array}{l}38 \mathrm{MS} \text { patients (38 RR, } 3 \text { IF/7M, } 39.5 \% \\
\text { untreated); } 38 \mathrm{HCs} \text { (sex-matched, } \\
3 \text { IF/7M) }\end{array}$ & $\begin{array}{l}\text { Eleven-item } \\
\text { Fatigue Scale }\end{array}$ & Salivary CAR test & $\begin{array}{l}\text { Higher CAR in the patient group } \\
\text { Association between recalled baseline } \\
\text { fatigue (but not same-day fatigue) and } \\
\text { CAR }\end{array}$ \\
\hline Akcali et $a^{28}$ & $\begin{array}{l}26 \text { fatigued MS patients (all RR, } \\
\text { I4F/I2M); } 28 \text { unfatigued MS patients } \\
\text { (all RR, I5F/I3M); } 87.1 \% \text { of cohort } \\
\text { treated; } 26 \mathrm{HCs}(13 \mathrm{~F} / / 3 \mathrm{M}) \text {; sex- } \\
\text { matched groups }\end{array}$ & FSS, NFI-MS & $\begin{array}{l}\text { ACTH, cortisol, } \alpha-M S H, \\
\beta-M S H, \gamma-M S H, \text { and CLIP }\end{array}$ & $\begin{array}{l}\text { Higher ACTH, cortisol, and MSH and } \\
\text { lower CLIP among MS patients compared } \\
\text { to HC; no significant differences between } \\
\text { fatigued and unfatigued MS patients } \\
\text { No correlation between fatigue and } \\
\text { hormones studied }\end{array}$ \\
\hline Téllez et a ${ }^{37}$ & $\begin{array}{l}29 \text { fatigued } M S \text { patients ( } 20 \mathrm{PP}, 9 \mathrm{SP} \text {, } \\
20 \mathrm{~F} / 9 \mathrm{M}, 5 \mathrm{I} .7 \% \text { treated); } 9 \text { unfatigued } \\
\mathrm{MS} \text { patients (5 PP, } 4 \mathrm{SP} \text {, sex-matched, } \\
5 \mathrm{~F} / 4 \mathrm{M}, 66.7 \% \text { treated) }\end{array}$ & FSS & $\begin{array}{l}\text { Serum levels of DHEA, } \\
\text { DHEA-sulfate conjugate, and } \\
\text { cortisol }\end{array}$ & $\begin{array}{l}\text { Lower levels of DHEA and its sulfated } \\
\text { conjugate among fatigued MS patients } \\
\text { Inverse correlation between fatigue and } \\
\text { DHEA levels }\end{array}$ \\
\hline \multicolumn{5}{|c|}{ Studies assessing the hypothalamic orexin A system } \\
\hline Papuć et al ${ }^{14}$ & $\begin{array}{l}28 \text { fatigued MS patients }(15 \mathrm{~F} / \mathrm{I} 3 \mathrm{M}) \text {; } \\
10 \text { unfatigued MS patients }(6 \mathrm{~F} / 4 \mathrm{M}) \text {; } \\
\text { cohort characteristics } 25 \mathrm{RR}, 13 \mathrm{SP} \text {, } \\
\text { all untreated; } 15 \mathrm{HCs}(8 \mathrm{~F} / 7 \mathrm{M}) \text {; sex- } \\
\text { matched groups }\end{array}$ & FSS & CSF levels of orexin A & $\begin{array}{l}\text { No group differences regarding orexin A } \\
\text { levels } \\
\text { Correlation between fatigue and orexin } \\
\text { A levels }\end{array}$ \\
\hline $\begin{array}{l}\text { Constantinescu } \\
\text { et } \mathrm{al}^{15}\end{array}$ & $\begin{array}{l}34 \mathrm{MS} \text { patients ( } 26 \mathrm{RR}, 2 \mathrm{SP}, 6 \mathrm{PP} \text {, } \\
22 \mathrm{~F} / \mathrm{I} 2 \mathrm{M} \text {, treatment NA); } 24 \text { patients } \\
\text { with other inflammatory neurological } \\
\text { diseases (7F/I7M); } 42 \text { patients with } \\
\text { noninflammatory neurological diseases; } \\
\text { significantly more females in MS- } \\
\text { patient group }\end{array}$ & FSS & CSF levels of orexin A & $\begin{array}{l}\text { No significant group differences regarding } \\
\text { orexin I levels } \\
\text { No correlations between CSF levels of } \\
\text { orexin } A \text { and fatigue }\end{array}$ \\
\hline \multicolumn{5}{|c|}{ Studies assessing other CSF markers } \\
\hline $\begin{array}{l}\text { Biberacher } \\
\text { et } \text { al }^{39}\end{array}$ & $\begin{array}{l}\text { Two phases: } 68 \mathrm{MS} \text { patients (discovery } \\
\text { cohort, } 7 \mathrm{CIS}, 60 \mathrm{RR}, \mathrm{I} \mathrm{SP}, 49 \mathrm{~F} / \mathrm{I} 9 \mathrm{M} \text {, } \\
77.9 \% \text { treated); } 8 \text { I MS patients } \\
\text { (validation cohort, } 9 \mathrm{CIS}, 7 \mathrm{I} \mathrm{RR}, \mathrm{I} \mathrm{SP} \text {, } \\
\text { 5IF/30M, } 75.3 \% \text { treated) }\end{array}$ & FSMC & 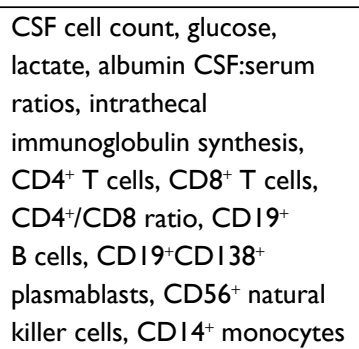 & $\begin{array}{l}\text { Group comparison NA } \\
\text { No correlations between fatigue and any } \\
\text { CSF parameter }\end{array}$ \\
\hline Brenner et $\mathrm{a}^{40}$ & $\begin{array}{l}47 \text { MS patients (all RR, 3IF/I6M, } \\
\text { untreated) }\end{array}$ & MFIS & CSF levels of IL6 and IL8 & $\begin{array}{l}\text { Group comparison NA } \\
\text { Correlation between fatigue and IL6 levels }\end{array}$ \\
\hline
\end{tabular}

Abbreviations: ACTH, adrenocorticotropic hormone; CAR, cortisol awakening response; CIS, clinical isolated syndrome; CLIP, corticotropin-like intermediate-lobe peptide; CSF, cerebrospinal fluid; Dex-CRH, dexamethasone-corticotropin-releasing hormone-suppression; DHEA, dehydroepiandrosterone; F, female; FSS, Fatigue Severity Scale; FSMC, Fatigue Scale for Motor and Cognitive Functions; HCs, healthy controls; HPA, hypothalamic-pituitary-adrenal; M, male; MFIS, Modified Fatigue Impact Scale; MS, multiple sclerosis; MSH, melanocyte-stimulating hormone; NA, not available, NFI, Neurological Fatigue Index; PP, primary progressive; RR, relapsing-remitting; SP, secondary progressive; VAS, visual analog scale.

\section{Peripheral inflammation and MS fatigue}

Immunodysregulation constitutes the core of the disease process in MS..$^{41-43}$ The role of peripheral inflammation in the development of MS fatigue has been considered in few immunological studies that assessed serum levels of cytokines, cytokine-producing cells, or other inflammatory markers. The first evidence on this matter dates back to $1990 .{ }^{44}$ In a series of eight fatigued MS patients, the authors assessed serum levels of IL2 and its soluble receptor, an interleukin that was suggested to intervene in CNS demyelination in MS and was previously found to be associated with the disease state in an animal MS model. The authors reported that in all patients, the variables studied were below the level of sensitivity of the test used (enzyme-linked immunosorbent assay [ELISA]), and thus denied the association between MS fatigue and 
IL2 levels. Afterward, Flachenecker and colleagues applied real-time polymerase chain reaction (RT-PCR) to compare the expression (mRNA) of circulating proinflammatory (ie, TNF $\alpha$, IFN $\gamma$ ) and anti-inflammatory cytokines (IL10) in fatigued and unfatigued MS patients. ${ }^{45}$ TNF $\alpha$ expression was heightened among fatigued patients, with no group differences regarding IFN $\gamma$ and IL10 expression. The role of TNF $\alpha$ has also been suggested in some studies that documented a decrease in TNF $\alpha$ levels following exercise therapy, a finding that was paralleled by an improvement in MS fatigue. ${ }^{46-48}$

In a similar way to these studies, the same cytokines were assessed in two trials by Heesen et al. ${ }^{25,49}$ ELISA was employed in both works. In the first, only fatigued MS patients were recruited and compared to healthy controls at baseline following a cognitive task that assessed psychological stress. ${ }^{49}$ No group difference was observed at baseline with regard to cytokine levels but following the cognitive task the MS group had relatively diminished IFN $\gamma$ response compared to the healthy group. No significant correlations were observed between fatigue scores and cytokine levels. In the second study, the authors recruited two groups of MS patients with and without fatigue and obtained positive findings. ${ }^{25}$ That is to say that, compared to unfatigued patients, the fatigued ones had higher proinflammatory cytokines (TNF $\alpha$ and IFN $\gamma$ ), with no group differences observed with regard to the anti-inflammatory cytokine (IL10). A correlation was also found between fatigue scores (MFIS and FSS) and TNF $\alpha$ and IFN $\gamma$ levels. The difference between the studies might lie in differences in the study populations, where the first considered only fatigued patients, whereas the second also considered an unfatigued patient group.

The same group of authors performed a third study that highlighted the role of IFN $\gamma$-producing $\mathrm{CD}^{+} \mathrm{T}$ cells as the only significant predictor of fatigue scores. ${ }^{27}$ The contribution of IFN $\gamma$ to the pathophysiology of MS fatigue was also assessed by Pokryszko-Dragan et al. ${ }^{50}$ Using flow cytometry, they studied the production of this cytokine by $\mathrm{CD} 3^{+} \mathrm{CD} 4^{+}$ $\mathrm{T}$ lymphocytes. Heightened IFN $\gamma$ production was observed among fatigued patients compared to unfatigued patients and healthy controls, a finding that also tended to correlate with fatigue scores (FSS and MFIS). However, when multiple regression analysis was run, fatigue scores were not linked to IFN $\gamma$. The role of interferon signaling was also highlighted in a pilot study by Mulero et al. ${ }^{51}$ Here, compared to healthy controls, fatigued MS patients had significant activation in genes participating in the systemic interferon response.

Another important factor in the context of MS is IL17 which appears to be implicated in glutamate-mediated excitotoxicity and thus may explain the potential link between inflammation and neurodegeneration in MS. ${ }^{52}$ The relationship between fatigue and IL17 levels has been addressed by three works that yielded inconsistent outcomes, with two studies confirming such a correlation ${ }^{47,53}$ and one denying it. ${ }^{56}$

Other circulating cytokines were the subject of a study by Malekzadeh et al, who compared serum levels of a panel of proinflammatory (IL1 $\beta$, IL2, IL6, IL8, IL12p70, IL17, TNF $\alpha$, and IFN $\gamma$ ) and anti-inflammatory cytokines (IL4, IL5, IL10, and IL13) in fatigued and unfatigued MS patients using an electrochemiluminescence-based multiplex immunoassay. ${ }^{53}$ In the absence of group differences with regard to these variables, a significant correlation was found between IL6 levels and fatigue scores. Of interest, the IL6 levels were found to diminish in another work following the administration of antifatigue pharmacological therapies such as amantadine and pemoline, a finding that was paralleled by fatigue improvement. ${ }^{54}$

An additional study by Akcali et al evaluated serum levels of TNF $\alpha$, IL10, and other interleukins (IL1 $\beta$, IL2, and IL35) in MS patients and healthy controls. ${ }^{28}$ Compared to healthy controls, the only group difference was observed with regard to IL35 and IL2, which were higher in the patient group. However, neither was there a difference between fatigued and unfatigued patients nor was there any correlation between fatigue scores and the markers considered.

Again, inconsistency in results across studies might have been related to cohort characteristics and sample-size difference, but also to other plausible factors. For instance, levels of pro/anti-inflammatory markers can fluctuate during the disease course and disease-modifying therapies can impact cytokine expression. ${ }^{28,55}$ To overcome this limitation, recent studies by Alvarenga-Filho et al enrolled drug-naïve MS patients. ${ }^{47,56}$ Here, higher IL6 and TNF $\alpha$ levels were observed among fatigued patients, ${ }^{47}$ and fatigue scores were correlated with IL6 and TNF $\alpha$ levels ${ }^{47,56}$ and tended to correlate with IFN $\gamma$ levels. ${ }^{47}$ Another factor to consider is differences in methods adopted in measuring cytokine levels. This is obviously illustrated with regard to IFN $\gamma$. In reality, IFN $\gamma$ was found to be unrelated to fatigue when using RT-PCR ${ }^{45}$ and a multiplex $\mathrm{kit}^{53}$ and associated or tended to associate with fatigue when using ELISA ${ }^{25,56}$ and flow cytometry. ${ }^{50}$ As such, these tests seem to have different sensitivity/specificity profiles, and this would hamper the possibility of drawing formal conclusions from the existing literature. Moreover, even when using ELISA, results might vary between in vivo and in vitro approaches. The best documentation of this variability can be found in the 
studies on IL17 (ie, serum-cytokine levels in vivo ${ }^{47,53,56}$ versus stimulated cytokines production in vitro ${ }^{47,56}$ ). In fact, one of these works simultaneously adopted both approaches, but only documented a significant correlation between fatigue and in vitro IL17 production. ${ }^{56}$ In addition, differences in statistical approaches might explain differences in results reported. While positive studies IFN- $\gamma$ employed group-comparison and correlation analysis, ${ }^{25,47,50,56}$ studies that failed to demonstrate this relationship adopted group comparison without correlation analysis ${ }^{45}$ or multiple regression analysis..$^{53}$

Given the role of T cells in the pathophysiology of MS, few works have addressed the relationship between circulating T-cell populations and MS fatigue and failed to document any association. Fatigued and unfatigued MS patients did not differ with regards to the amount of IFN $\gamma$-producing
$\mathrm{CD}^{+} \mathrm{CD}^{+} \mathrm{T}$ lymphocytes in one study ${ }^{50}$ or the number of leukocyte and lymphocyte subsets including regulatory $\mathrm{T}$ cells and its suppressive function in another study. ${ }^{57}$

Finally, three studies included markers of peripheral inflammation in the assessment of MS fatigue. In the first, Giovannoni et al failed to demonstrate any relationship between fatigue and serum (ie, CRP, soluble ICAM1) or urinary (daily urinary neopterin excretion measured over 2 weeks) markers. ${ }^{58}$ Similarly, in a second study by Flachenecker et al, the erythrocyte-sedimentation rate, a marker of systemic inflammation, did not differ between fatigued and unfatigued MS patients. ${ }^{45}$ Finally, in a third study by Adamczyk-Sowa et al, no correlation was found between MS fatigue and plasma lipid hydroxyperoxides or homocysteine concentration, which are markers of oxidation. ${ }^{59}$ Table 2 summarizes these studies.

Table 2 Studies assessing the relationship between multiple sclerosis fatigue and peripheral inflammation

\begin{tabular}{|c|c|c|c|c|}
\hline Study & Population & $\begin{array}{l}\text { Fatigue } \\
\text { assessment }\end{array}$ & Method & Results \\
\hline \multicolumn{5}{|c|}{ Studies assessing peripheral cytokines } \\
\hline $\begin{array}{l}\text { Rudick and } \\
\text { Barna }^{44}\end{array}$ & $\begin{array}{l}\text { Eight fatigued MS patients (disease } \\
\text { details } N A, 6 F / 2 M \text { ); } 50 \mathrm{HCs}\end{array}$ & NA & $\begin{array}{l}\text { Serum levels of IL2 and its } \\
\text { receptor (using ELISA) }\end{array}$ & $\begin{array}{l}\text { No group difference with regard to IL2 or its } \\
\text { receptor level } \\
\text { Correlation NA }\end{array}$ \\
\hline $\begin{array}{l}\text { Flachenecker } \\
\text { et } \mathrm{al}^{45}\end{array}$ & $\begin{array}{l}26 \text { fatigued MS patients; } \\
\text { II unfatigued MS patients; cohort } \\
\text { characteristics, } 29 \text { RR, } 8 \text { SP, } \\
\text { 27F/IOM, 54\% treated }\end{array}$ & FSS & $\begin{array}{l}\text { Serum mRNA expression of } \\
\text { IFN } \gamma, T N F \alpha \text {, and ILI0 (using } \\
\text { RT-PCR) }\end{array}$ & $\begin{array}{l}\text { Higher TNF } \alpha \text { (but not IFN } \gamma \text { or ILI0) mRNA } \\
\text { expression among fatigued patients } \\
\text { Correlation analysis between fatigue and } \\
\text { cytokine mRNA expression NA }\end{array}$ \\
\hline $\begin{array}{l}\text { Heesen } \\
\text { et al }{ }^{49}\end{array}$ & $\begin{array}{l}23 \text { fatigued MS patients (19 RR, } \\
3 \mathrm{SP} \text {, I PP, I8F/5M, 60.9\% treated); } \\
25 \mathrm{HCs} \text { (sex-matched, } 20 \mathrm{~F} / 5 \mathrm{M} \text { ) }\end{array}$ & MFIS & $\begin{array}{l}\text { Whole-blood stimulatory } \\
\text { capacity for TNF } \alpha \text {, IFN } \gamma \text {, } \\
\text { and ILI0 (using ELISA); } \\
\text { cognitive task to examine the } \\
\text { immunoresponse (cytokines) } \\
\text { to psychological stress }\end{array}$ & $\begin{array}{l}\text { No significant group difference in baseline } \\
\text { cytokines } \\
\text { Blunted response of IFN } \gamma \text { among MS patients } \\
\text { following psychological stress (no group } \\
\text { difference in TNF } \alpha \text { or ILI } 0 \text { responses) } \\
\text { No correlation between fatigue and cytokine } \\
\text { levels }\end{array}$ \\
\hline $\begin{array}{l}\text { Heesen } \\
\text { et } \mathrm{al}^{25}\end{array}$ & $\begin{array}{l}\text { I5 fatigued MS patients (6 RR, } 8 \\
\text { SP, I PP, 9F/6M, 66.7\% treated); } \\
\text { I5 unfatigued MS patients (II RR, } \\
2 \text { SP, } 2 \text { PP, sex-matched, 9F/6M, } \\
60 \% \text { treated) }\end{array}$ & MFIS, FSS & $\begin{array}{l}\text { Whole-blood stimulatory } \\
\text { capacity for TNF } \alpha \text {, IFN } \gamma \text {, and } \\
\text { ILI0 (using ELISA) }\end{array}$ & $\begin{array}{l}\text { Higher levels of TNF } \alpha \text { and IFN } \gamma \text { (but not } \\
\text { ILIO levels) in fatigued MS patients } \\
\text { Correlation between fatigue scores of TNF } \alpha \\
\text { and IFN } \gamma\end{array}$ \\
\hline Gold et $\mathrm{a}^{27}$ & $\begin{array}{l}44 \mathrm{MS} \text { patients (all RR, all female, } \\
59 \% \text { treated) }\end{array}$ & MFIS, FSS & $\begin{array}{l}\text { Serum intracellular levels of } \\
\text { cytokines IFN } \gamma \text { and TNF } \alpha \\
\text { (using flow cytometry) }\end{array}$ & $\begin{array}{l}\text { Frequency of IFN } \gamma \text {-producing } \mathrm{CD} 8^{+} \mathrm{T} \text { cells } \\
\text { predicted of fatigue scores (regression } \\
\text { analysis) }\end{array}$ \\
\hline $\begin{array}{l}\text { Pokryszko- } \\
\text { Dragan } \\
\text { et } \mathrm{al}^{50}\end{array}$ & $\begin{array}{l}20 \text { fatigued MS patients; } 20 \\
\text { unfatigued MS patients; cohort } \\
\text { characteristics, } 30 \text { RR, I0 SP, } \\
\text { 30F/IOM, untreated; } 25 \mathrm{HCs} \text { (sex } \\
\text { NA) }\end{array}$ & MFIS, FSS & $\begin{array}{l}\text { Levels of IFN } \gamma \text { (using flow } \\
\text { cytometry) }\end{array}$ & $\begin{array}{l}\text { Higher IFN } \gamma \text { production among fatigued MS } \\
\text { A trend toward correlation between fatigue } \\
\text { and IFN } \gamma\end{array}$ \\
\hline $\begin{array}{l}\text { Malekzadeh } \\
\text { et al }{ }^{53}\end{array}$ & $\begin{array}{l}\text { 2I fatigued MS patients (I5 RR, } 5 \\
\text { PP/SP, I missing, IOF/7M, } 47.6 \% \\
\text { treated); I } 4 \text { unfatigued MS patients } \\
\text { (I I RR, } 3 \text { PP/SP, sex-matched, } \\
\text { IOF/4M, 50\% treated) }\end{array}$ & $\begin{array}{l}\text { Self-reported } \\
\text { checklist: } \\
\text { individual } \\
\text { strength, } \\
\text { fatigue } \\
\text { subscale }\end{array}$ & $\begin{array}{l}\text { Serum levels of ILI } \beta \text {, IL2, } \\
\text { IL6, IL8, ILI 2p70, ILI7, } \\
\text { TNF } \alpha \text {, and IFN } \gamma \text {, IL4, } \\
\text { IL5, ILI0, and ILI3 (using } \\
\text { electrochemiluminescence- } \\
\text { based multiplex immunoassay) }\end{array}$ & $\begin{array}{l}\text { No group differences with regard to } \\
\text { variables measured } \\
\text { Association between fatigue and IL6 levels } \\
\text { (regression analysis) }\end{array}$ \\
\hline
\end{tabular}

(Continued) 
Table 2 (Continued)

\begin{tabular}{|c|c|}
\hline Study & Population \\
\hline $\begin{array}{l}\text { Mulero } \\
\text { et } \mathrm{al}^{51}\end{array}$ & $\begin{array}{l}\text { Seven fatigued MS patients (all } \\
\text { RR, } 5 F / 2 M, 85.7 \% \text { treated); } 7 \mathrm{HCs} \\
\text { (details NA) }\end{array}$ \\
\hline $\begin{array}{l}\text { Alvarenga- } \\
\text { Filho et al }{ }^{47}\end{array}$ & $\begin{array}{l}\text { I } 8 \mathrm{MS} \text { patients (all RR, I5F/3M, } \\
\text { untreated); I0 HCs (age-matched } \\
8 \mathrm{~F} / 2 \mathrm{M})\end{array}$ \\
\hline $\begin{array}{l}\text { Alvarenga- } \\
\text { Filho et al }{ }^{56}\end{array}$ & $\begin{array}{l}\text { I } 5 \text { fatigued MS patients (all RR, } \\
\text { IIF/4M, untreated); I } 5 \text { unfatigued } \\
\text { MS (all RR, sex-matched, IOF/5M, } \\
\text { untreated) }\end{array}$ \\
\hline
\end{tabular}

$\begin{aligned} & \text { Fatigue } \\ & \text { assessment }\end{aligned}$
MFIS
FSS

Method Results

Whole-blood gene expression Activation of IFN-response genes among
(using microarrays and RT- fatigued MS patients PCR)

In vivo and in vitro assessment of peripheral levels of IL6, ILI 10, IL2I, IL22, ILI7, TNF $\alpha$, and IFN $\gamma$ (using ELISA)

Correlation NA

Higher IFN $\gamma$, IL6, TNF $\alpha$, ILI 7, and IL22

among MS patients

In vivo: correlation between fatigue and each of IL6 and TNF $\alpha$ and a trend toward a correlation with IFN $\gamma$

In vitro: correlation between fatigue and of IL6, TNF $\alpha$, IFN $\gamma$, and IL22 levels

FSS In vivo and in vitro assessment of peripheral Higher IL6 and TNF $\alpha$ levels in fatigued MS patients

levels of IL6, ILI0, ILI2, ILI7, In vivo: correlation between fatigue and IL2I, IL22, IL23, TNF $\alpha$, and IL6 and TNF $\alpha$ levels and a trend toward a IFN $\gamma$ (using ELISA)

correlation between fatigue and IFN $\gamma$ In vitro: correlation between fatigue and ILI $\beta$, IL6, ILI7, IL22, and IL23 levels

Akcali et al ${ }^{28} \quad 26$ fatigued MS patients (I4F/I2M); 28 unfatigued $M S$ patients

FSS, NFI-MS

Serum ILI $\beta$, TNF $\alpha$, IL35, IL2, and ILIO (using ELISA) Higher IL35 and IL2 (but not ILI $\beta$, ILI 0, or (I5F/I3M); cohort characteristics, all RR, $87.1 \%$ treated; $26 \mathrm{HCs}$ (I3F/I3M); sex-matched groups

TNF $\alpha$ ) in the patient group compared to $\mathrm{HCs}$

No group differences between fatigued and unfatigued patients for any measure No correlation between fatigue and any cytokines studied

\begin{tabular}{|c|c|c|c|}
\hline \multicolumn{4}{|c|}{ Studies assessing peripheral blood-cell populations } \\
\hline Yaldizli & 20 fatigued MS patients (I 3 RR, 6 & FSS & Lymphocyte subsets in \\
\hline \multirow{5}{*}{ et $\mathrm{a}^{57}$} & SP, I PP, I3F/7M, untreated); 20 & & peripheral blood mononuclear \\
\hline & unfatigued MS patients ( 12 RR, 7 & & cell cultures (using flow \\
\hline & SP, IPP, I2F/8M, untreated); 19 & & cytometry); suppressive \\
\hline & HCs; sex-matched groups & & function of regulatory $\mathrm{T}$ cells \\
\hline & & & (using antigen stimulation) \\
\hline
\end{tabular}

$\begin{array}{ll}\text { Pokryszko- } & 20 \text { fatigued MS patients; } 20 \\ \text { Dragan } & \text { unfatigued MS patients; cohort } \\ \text { et al }{ }^{50} & \text { characteristics, 30 RR, 10 SP, } \\ & \text { 30F/IOM, untreated; } 25 \mathrm{HCs} \\ & (\text { sex NA) }\end{array}$

MFIS, FSS

Percentage of IFN $\gamma$-positive $\mathrm{CD}^{+}{ }^{+} \mathrm{CD} 4^{+} \mathrm{T}$ lymphocytes (using flow cytometry)

No difference in leukocyte and lymphocyte subsets, including regulatory $T$ cells between fatigued and unfatigued MS patients The entire patient group tended to have lower suppressive regulatory T-cell activity compared to HCs, with no differences between fatigued and unfatigued patients Correlation NA

No group difference with regard to percentage of IFN $\gamma$-positive $\mathrm{CD}^{+} \mathrm{CD} 4^{+} \mathrm{T}$ lymphocytes

No correlation between fatigue and percentage of IFN $\gamma$-positive $\mathrm{CD}^{+} \mathrm{CD} 4^{+} \mathrm{T}$ lymphocytes

\section{Studies assessing other peripheral markers}

\begin{tabular}{|c|c|c|c|c|}
\hline $\begin{array}{l}\text { Giovannoni } \\
\text { et a }{ }^{58}\end{array}$ & $\begin{array}{l}38 \mathrm{MS} \text { patients ( } 16 \mathrm{RR}, 9 \mathrm{SP}, 13 \\
\mathrm{PP}, \mathrm{I} / \mathrm{F} / 2 \mathrm{IM} \text {, all untreated) }\end{array}$ & FQS, FSS & $\begin{array}{l}\text { Serum CRP and sICAM-I } \\
\text { levels; urinary neopterin } \\
\text { excretion (measured daily for } \\
2 \text { weeks) }\end{array}$ & $\begin{array}{l}\text { Patients with raised serum CRP had higher } \\
\text { FSS (but not FQS) scores than patients with } \\
\text { normal CRP levels } \\
\text { No correlation between fatigue (FSS, FQS) } \\
\text { and any variable measured }\end{array}$ \\
\hline $\begin{array}{l}\text { Flachenecker } \\
\text { et al }{ }^{45}\end{array}$ & $\begin{array}{l}26 \text { fatigued MS patients; II } \\
\text { unfatigued MS patients; cohort } \\
\text { characteristics, } 29 \text { RR, } 8 \mathrm{SP} \text {, } \\
27 \mathrm{~F} / \mathrm{IOM}, 54 \% \text { treated }\end{array}$ & FSS & Serum ESR & $\begin{array}{l}\text { No group differences in ESR values } \\
\text { Correlation analysis NA }\end{array}$ \\
\hline $\begin{array}{l}\text { Adamczyk- } \\
\text { Sowa et al }{ }^{59}\end{array}$ & $\begin{array}{l}\text { I02 MS patients (85 RR, I7 PP/SP, } \\
\text { 67F/35M, 79.4\% treated); } 20 \mathrm{HCs} \\
\text { (sex-matched) }\end{array}$ & MFIS & $\begin{array}{l}\text { Plasma lipid hydroxyperoxides } \\
\text { and homocysteine } \\
\text { concentrations }\end{array}$ & $\begin{array}{l}\text { Higher lipid-hydroxyperoxide levels among } \\
\text { MS patients compared to HCs } \\
\text { No correlation between fatigue and } \\
\text { biochemical measures }\end{array}$ \\
\hline
\end{tabular}

Abbreviations: ELISA, enzyme-linked immunosorbent assay; ESR, erythrocyte-sedimentation rate; F, female; FSS, Fatigue Severity Scale; FQS, Fatigue Questionnaire Scale; HCs, healthy controls; M, male; MFIS, Modified Fatigue Impact Scale; MS, multiple sclerosis; NA, not available, NFI, Neurological Fatigue Index; PP, primary progressive; RR, relapsing-remitting; RT-PCR, real-time polymerase chain reaction; SP, secondary progressive. 


\section{Conclusion}

This work has evaluated the contribution of central and peripheral inflammatory processes to MS fatigue. Among the selected studies dealing with central inflammatory and neuroendocrine processes, an inconsistency existed regarding the relationship between fatigue and orexin A system (present in one study, ${ }^{14}$ absent in one ${ }^{15}$ ), the HPA axis (present in two studies, ${ }^{30,34}$ absent in five studies ${ }^{24-28}$ ), and some CSF markers (present in one study assessing cytokines ${ }^{40}$ absent in one study assessing cellular, humoral, and other CSF parameters ${ }^{39}$ ). As for peripheral markers, although there was scarcity in the available data, serum proinflammatory cytokines (ie, IL6, TNF $\alpha$, and IFN $\gamma$ ) seemed to be associated with MS fatigue. However, given the existence of some conflicting data in this domain, such an association merits further investigation. Finally, concerning T-cell population (ie, $\mathrm{CD}^{+} \mathrm{CD}^{+} \mathrm{T}$ lymphocytes ${ }^{50}$ or regulatory $\mathrm{T}$ cells ${ }^{57}$ ) or peripheral markers of inflammation (ie, CRP, erythrocyte-sedimentation rate, and soluble ICAM1), ${ }^{45,58,59} \mathrm{few}$ data were available, and these studies failed to find a link between MS fatigue and these measures. It is also worth noting that studies differed greatly in the clinical characteristics of their cohorts, especially concerning treatment profiles. The fact that MS treatment can modulate the inflammatory milieu ${ }^{30,31}$ would stand behind the differences observed in study outcomes, with studies including untreated patients yielding positive results on the relationship between fatigue and inflammation..$^{14,40,47,50,56}$ Of note, several trials have documented differences in immune/inflammatory profiles between treated and naïve MS patients. That is to say, downregulation of proinflammatory cytokines was observed among MS patients treated with disease-modifying therapies such as IFN $\beta,{ }^{60-63}$ glatiramer acetate,${ }^{64}$ dimethyl fumarate,${ }^{65}$ fingolimod, ${ }^{66}$ natalizumab ${ }^{67}$ and teriflunomide. ${ }^{68}$

Another issue to consider is the possible impact of MS treatments on fatigue per se. Few reports are available on this matter. In a cross-sectional study, higher fatigue rates were observed among MS patients treated with IFN $\beta$ or glatiramer acetate compared to age- and sex-matched patients receiving natalizumab ${ }^{69}$ In other works, rituximab seemed to induce fatigue in MS patients, ${ }^{70}$ natalizumab appeared to improve fatigue, ${ }^{71-74}$ and fingolimod did not seem to modify symptom severity. ${ }^{75}$ Therefore, more research is needed to understand the potential effects of MS therapies on fatigue perception and cytokine profiles.

Another difference among studies concerned fatigue scales, which consisted of the FSS, MFIS, FSMC, visual analogue scale for fatigue, eleven-item Fatigue Scale, Neurological Fatigue Index - MS, self-reported checklist - individual strength (fatigue subscale), and Fatigue Questionnaire Scale. This adds more difficulty in comparing study outcomes. While some of these scales (eg, FSS) mainly address the physical component of fatigue, other scales (eg MFIS) reflect the physical, and, the cognitive and psychosocial dimensions of this symptom. This difference might not have had a large impact on group differences (fatigued versus unfatigued) but may have affected the correlation between fatigue severity and cytokine levels and could partly explain the discrepancies observed among studies.

Using different immunological techniques (ie, ELISA, RT-PCR, genetic analysis, flow cytometry, and electrochemiluminescence-based multiplex immunoassay) might have been behind interstudy differences, particularly those evaluating peripheral cytokines. Another point to consider is the relationship between sex, hormones, and immunodysregulation. Like many autoimmune diseases, MS is more prevalent in women than men, and hormones seem to exert an immunomodulatory effect and might influence damage repair in the CNS. ${ }^{76}$ Interestingly, sex dysmorphism was observed with regard to cytokine production in MS patients. ${ }^{77}$ In this context, it is of importance to note that although some studies controlled for sex effects by including sex-matched controls, ${ }^{14,24,25,28,30,33,37,47,49,53,56,57,59}$ other studies enrolled cohorts predominantly ${ }^{15,39,40,45}$ or exclusively ${ }^{26}$ composed of female patients or did not provide sufficient details on the matter. ${ }^{24,44,45,50,51}$ Therefore, future work could benefit from comparing fatigue and cytokine production between male and female patients.

Moreover, studying the impact of environmental, genetic, and epigenetic MS risk factors on MS fatigue would be of great interest. These factors include ultraviolet-radiation exposure, vitamin D intake, smoking, dietary, and exercise habits, and body-mass index. ${ }^{78}$ It is also of importance to control for some confounders that occur frequently in MS and can impact MS fatigue. These include physical disability, ${ }^{6}$ emotional symptoms, ${ }^{79,80}$ and sleep disorders. ${ }^{81}$ There is still a long way to go to define the utility and place of the aforementioned measures in clinical wards. Future large-scale studies are critically needed to conclude on this matter and would benefit from comparing the relationship between fatigue and inflammation in patients with different disease phenotypes (RR vs primary progressive vs secondary progressive) with and without disease-modifying drugs. From this perspective, applying different measures might help to decide on the optimal target to serve as an immunological surrogate of MS fatigue. Facing the subjective nature of fatigue scales, developing objective biological markers for fatigue, as those visited here, would be of great help. 


\section{Disclosure}

SSA has received travel grants or compensation from Genzyme, Biogen, Novartis, and Roche. The authors report no other conflicts of interest in this work.

\section{References}

1. Sospedra M, Martin R. Immunology of multiple sclerosis. Annu Rev Immunol. 2005;23:683-747.

2. Dendrou CA, Fugger L, Friese MA. Immunopathology of multiple sclerosis. Nat Rev Immunol. 2015;15:545-558.

3. Compston A, Coles A. Multiple sclerosis. Lancet. 2008;372:1502-1517.

4. Chalah MA, Riachi N, Ahdab R, Créange A, Lefaucheur JP, Ayache SS. Fatigue in multiple sclerosis: neural correlates and the role of noninvasive brain stimulation. Front Cell Neurosci. 2015;9:460.

5. Centonze D, Muzio L, Rossi S, Furlan R, Bernardi G, Martino G. The link between inflammation, synaptic transmission and neurodegeneration in multiple sclerosis. Cell Death Differ. 2010;17:1083-1091.

6. Ayache SS, Chalah MA. Fatigue in multiple sclerosis: insights into evaluation and management. Neurophysiol Clin. 2017;47:139-171.

7. Freal JE, Kraft GH, Coryell JK. Symptomatic fatigue in multiple sclerosis. Arch Phys Med Rehabil. 1984;65:135-138.

8. Moher D, Liberati A, Tetzlaff J, Altman DG. Preferred reporting items for systematic reviews and meta-analyses: the PRISMA statement. BMJ. 2009;339:b2535.

9. Tsujino N, Sakurai T. Role of orexin in modulating arousal, feeding, and motivation. Front Behav Neurosci. 2013;7:28.

10. Kiyashchenko LI, Mileykovskiy BY, Maidment N, et al. Release of hypocretin (orexin) during waking and sleep states. J Neurosci. 2002;22:5282-5286.

11. Grossberg AJ, Zhu X, Leinninger GM, et al. Inflammation-induced lethargy is mediated by suppression of orexin neuron activity. J Neurosci. 2011;31:11376-11386.

12. Oka Y, Kanbayashi T, Mezaki T, et al. Low CSF hypocretin-1/orexin-A associated with hypersomnia secondary to hypothalamic lesion in a case of multiple sclerosis. J Neurol. 2004;251:885-886.

13. Kato T, Kanbayashi T, Yamamoto K, et al. Hypersomnia and low CSF hypocretin-1 (orexin-A) concentration in a patient with multiple sclerosis showing bilateral hypothalamic lesions. Intern Med. 2003;42:743-745.

14. Papuć E, Stelmasiak Z, Grieb P, Paweł G, Rejdak K. CSF hypocretin-1 concentrations correlate with the level of fatigue in multiple sclerosis patients. Neurosci Lett. 2010;474:9-12.

15. Constantinescu CS, Niepel G, Patterson M, et al. Orexin A (hypocretin-1) levels are not reduced while cocaine/amphetamine regulated transcript levels are increased in the cerebrospinal fluid of patients with multiple sclerosis: no correlation with fatigue and sleepiness. J Neurol Sci. 2011;307:127-131.

16. Boddum K, Hansen MH, Jennum PJ, Kornum BR. Cerebrospinal fluid hypocretin-1 (orexin-a) level fluctuates with season and correlates with day length. PLoS One. 2016;11:e0151288.

17. Limone P, Ferrero B, Calvelli P, et al. Hypothalamic-pituitary-adrenal axis function and cytokine production in multiple sclerosis with or without interferon- $\beta$ treatment. Acta Neurol Scand. 2002;105:372-377.

18. Grasser A, Möller A, Backmund H, Yassouridis A, Holsboer F. Heterogeneity of hypothalamic-pituitary-adrenal system response to a combined dexamethasone-CRH test in multiple sclerosis. Exp Clin Endocrinol Diabetes. 1996;104:31-37.

19. Michelson D, Stone L, Galliven E, et al. Multiple sclerosis is associated with alterations in hypothalamic-pituitary-adrenal axis function. J Clin Endocrinol Metab. 1994;79:848-853.

20. Bergh FT, Kümpfel T, Trenkwalder C, Rupprecht R, Holsboer F. Dysregulation of the hypothalamo-pituitary-adrenal axis is related to the clinical course of MS. Neurology. 1999;53:772-777.

21. Ysrraelit MC, Gaitán MI, Lopez AS, Correale J. Impaired hypothalamicpituitary-adrenal axis activity in patients with multiple sclerosis. Neurology. 2008;71:1948-1954.
22. Melief J, de Wit SJ, van Eden CG, et al. HPA axis activity in multiple sclerosis correlates with disease severity, lesion type and gene expression in normal-appearing white matter. Acta Neuropathol. 2013;126:237-249.

23. Huitinga I, Erkut ZA, van Beurden D, Swaab DF. Impaired hypothalamus pituitary-adrenal axis activity and more severe multiple sclerosis with hypothalamic lesions. Ann Neurol. 2004;55:37-45.

24. Heesen C, Gold SM, Raji A, Wiedemann K, Schulz KH. Cognitive impairment correlates with hypothalamo-pituitary-adrenal axis dysregulation in multiple sclerosis. Psychoneuroendocrinology. 2002;27:505-517.

25. Heesen C, Nawrath L, Reich C, Bauer N, Schulz KH, Gold SM. Fatigue in multiple sclerosis: an example of cytokine mediated sickness behaviour? J Neurol Neurosurg Psychiatry. 2006;77:34-39.

26. Heesen C, Schulz KH, Fiehler J, et al. Correlates of cognitive dysfunction in multiple sclerosis. Brain Behav Immun. 2010;24:1148-1155.

27. Gold SM, Krüger S, Ziegler KJ, at al. Endocrine and immune substrates of depressive symptoms and fatigue in multiple sclerosis patients with comorbid major depression. J Neurol Neurosurg Psychiatry. 2011;82:814-818.

28. Akcali A, Zengin F, Aksoy SN, Zengin O. Fatigue in multiple sclerosis: is it related to cytokines and hypothalamic-pituitary-adrenal axis? Mult Scler Relat Disord. 2017;15:37-41.

29. Shishioh-Ikejima N, Ogawa T, Yamaguti K, Watanabe Y, Kuratsune H, Kiyama $\mathrm{H}$. The increase of alpha-melanocyte-stimulating hormone in the plasma of chronic fatigue syndrome patients. BMC Neurol. 2010;10:73.

30. Gottschalk M, Kümpfel T, Flachenecker P, et al. Fatigue and regulation of the hypothalamo-pituitary-adrenal axis in multiple sclerosis. Arch Neurol. 2005;62:277-280.

31. Kümpfel T, Schwan M, Weber F, Holsboer F, Trenkwalder C, Bergh FT. Hypothalamo-pituitary-adrenal axis activity evolves differentially in untreated versus treated multiple sclerosis. Psychoneuroendocrinology. 2014;45:87-95.

32. Dunn AJ. Effects of the IL-1 receptor antagonist on the IL-1- and endotoxin-induced activation of the HPA axis and cerebral biogenic amines in mice. Neuroimmunomodulation. 2000;7:36-45.

33. Powell DJ, Moss-Morris R, Liossi C, Schlotz W. Circadian cortisol and fatigue severity in relapsing-remitting multiple sclerosis. Psychoneuroendocrinology. 2015;56:120-131.

34. Clow A, Hucklebridge F, Stalder T, Evans P, Thorn L. The cortisol awakening response: more than a measure of HPA axis function. Neurosci Biobehav Rev. 2010;35:97-103.

35. Vogl D, Falk W, Dorner M, Schölmerich J, Straub RH. Serum levels of pregnenolone and 17-hydroxypregnenolone in patients with rheumatoid arthritis and systemic lupus erythematosus: relation to other adrenal hormones. J Rheumatol. 2003;30:269-275.

36. Tengstrand B, Carlström K, Fellander-Tsai L, Hafström I. Abnormal levels of serum dehydroepiandrosterone, estrone, and estradiol in men with rheumatoid arthritis: high correlation between serum estradiol and current degree of inflammation. J Rheumatol. 2003;30:2338-2343.

37. Téllez N, Comabella M, Julià E, et al. Fatigue in progressive multiple sclerosis is associated with low levels of dehydroepiandrosterone. Mult Scler. 2006;12:487-494.

38. Calabrese VP, Isaacs ER, Regelson W. Dehydroepiandrosterone in multiple sclerosis: positive effects on the fatigue syndrome in a non-randomized study. In: Kalimi M, Regelson W editors. The Biological Role of Dehydroepiandrosterone (DHEA). Berlin: de Gruyter; 1990:95-100

39. Biberacher V, Schmidt P, Selter RC, et al. Fatigue in multiple sclerosis: associations with clinical, MRI and CSF parameters. Mult Scler. Epub 2017 May 1.

40. Brenner P, Granqvist M, Königsson J, al Nimer F, Piehl F, Jokinen J. Depression and fatigue in multiple sclerosis: relation to exposure to violence and cerebrospinal fluid immunomarkers. Psychoneuroendocrinology. 2018;89:53-58.

41. Rovaris M, Barnes D, Woodrofe N, et al. Patterns of disease activity in multiple sclerosis patients: a study with quantitative gadolinium enhanced brain MRI and cytokine measurement in different clinical subgroups. J Neurol. 1996;243:536-542. 
42. Khademi M, Wallström E, Andersson M, Piehl F, Di Marco R, Olsson T. Reduction of both pro- and anti-inflammatory cytokines after 6 months of interferon $\beta$-1a treatment of multiple sclerosis. J Neuroimmunol. 2000;103:202-210.

43. Baraczka K, Pozsonyi T, Szüts I, Ormos G, Nékám K. Increased levels of tumor necrosis alpha and soluble vascular endothelial adhesion molecule-1 in the cerebrospinal fluid of patients with connective tissue diseases and multiple sclerosis. Acta Microbiol Immunol Hung. 2003;50:339-348.

44. Rudick RA, Barna BP. Serum interleukin 2 and soluble interleukin 2 receptor in patients with multiple sclerosis who are experiencing severe fatigue. Arch Neurol. 1990;47:254-255.

45. Flachenecker P, Bihler I, Weber F, Gottschalk M, Toyka KV, Rieckmann P. Cytokine mRNA expression in patients with multiple sclerosis and fatigue. Mult Scler. 2004;10:165-169.

46. Kierkegaard M, Lundberg IE, Olsson T, et al. High-intensity resistance training in multiple sclerosis: an exploratory study of effects on immune markers in blood and cerebrospinal fluid, and on mood, fatigue, healthrelated quality of life, muscle strength, walking and cognition. J Neurol Sci. 2016;362:251-257.

47. Alvarenga-Filho H, Sacramento PM, Ferreira TB, et al. Combined exercise training reduces fatigue and modulates the cytokine profile of T-cells from multiple sclerosis patients in response to neuromediators. J Neuroimmunol. 2016;293:91-99.

48. Mokhtarzade M, Ranjbar R, Majdinasab N, Patel D, Shamsi MM. Effect of aerobic interval training on serum IL-10, TNF $\alpha$, and adipokines levels in women with multiple sclerosis: possible relations with fatigue and quality of life. Endocrine. 2017;57:262-271.

49. Heesen C, Koehler G, Gross R, Tessmer W, Schulz KH, Gold SM. Altered cytokine responses to cognitive stress in multiple sclerosis patients with fatigue. Mult Scler. 2005;11:51-57.

50. Pokryszko-Dragan A, Frydecka I, Kosmaczewska A, et al. Stimulated peripheral production of interferon-gamma is related to fatigue and depression in multiple sclerosis. Clin Neurol Neurosurg. 2012;114:1153-1158.

51. Mulero P, Almansa R, Neri MJ, et al. Improvement of fatigue in multiple sclerosis by physical exercise is associated to modulation of systemic interferon response. J Neuroimmunol. 2015;280:8-11.

52. Kostic M, Zivkovic N, Cvetanovic A, Stojanovic I, Colic M. IL-17 signaling in astrocytes promotes glutamate excitotoxicity: indications for the link between inflammatory and neurodegenerative events in multiple sclerosis. Mult Scler Relat Disord. 2017;11:12-17.

53. Malekzadeh A, van de Geer-Peeters W, de Groot V, Teunissen CE, Beckerman H. Fatigue in patients with multiple sclerosis: is it related to pro- and anti-inflammatory cytokines? Dis Markers. 2015;2015:758314

54. Bertolone K, Coyle PK, Krupp LB, Doscher CA. Cytokine correlates of fatigue in multiple sclerosis. Neurology. 1993;43:A356.

55. Jafarzadeh A, Jamali M, Mahdavi R, et al. Circulating levels of interleukin-35 in patients with multiple sclerosis: evaluation of the influences of FOXP3 gene polymorphism and treatment program. J Mol Neurosci. 2015;55:891-897.

56. Alvarenga-Filho $\mathrm{H}$, Salles $\mathrm{M}$, Hygino J, et al. Fatigue favors in vitro Th1 and Th17-like cell expansion and reduces corticoid sensitivity in MS patients. J Neuroimmunol. 2017;303:81-89.

57. Yaldizli O, Kumar M, Vago S, Kreuzfelder E, Limmroth V, Putzki N. Fatigue is not associated with impaired function of regulatory T cells in untreated patients with multiple sclerosis. Eur Neurol. 2009;62:321-326.

58. Giovannoni G, Thompson AJ, Miller DH, Thompson EJ. Fatigue is not associated with raised inflammatory markers in multiple sclerosis. Neurology. 2001;57:676-681.

59. Adamczyk-Sowa M, Sowa P, Adamczyk J, et al. Effect of melatonin supplementation on plasma lipid hydroperoxides, homocysteine concentration and chronic fatigue syndrome in multiple sclerosis patients treated with interferons-beta and mitoxantrone. J Physiol Pharmacol. 2016;67:235-242.
60. Losy J, Michałowska-Wender G. In vivo effect of interferon- $\beta$ 1a on interleukin-12 and TGF- $\beta_{1}$ cytokines in patients with relapsing-remitting multiple sclerosis. Acta Neurol Scand. 2002;106:44-46.

61. Zhang X, Markovic-Plese S. Interferon beta inhibits the Th17 cellmediated autoimmune response in patients with relapsing-remitting multiple sclerosis. Clin Neurol Neurosurg. 2010;112:641-645.

62. Ramgolam VS, Markovic-Plese S. Interferon-beta inhibits Th17 cell differentiation in patients with multiple sclerosis. Endocr Metab Immune Disord Drug Targets. 2010;10:161-167.

63. Ramgolam VS, Sha Y, Jin J, Zhang X, Markovic-Plese S. IFN- $\beta$ inhibits human Th17 cell differentiation. J Immunol. 2009;183:5418-5427.

64. Oreja-Guevara C, Ramos-Cejudo J, Aroeira LS, Chamorro B, DiezTejedor E. TH1/TH2 cytokine profile in relapsing-remitting multiple sclerosis patients treated with glatiramer acetate or natalizumab. $B M C$ Neurol. 2012;12:95.

65. Mills EA, Ogrodnik MA, Plave A, Mao-Draayer Y. Emerging understanding of the mechanism of action for dimethyl fumarate in the treatment of multiple sclerosis. Front Neurol. 2018;9:5.

66. Su K, Zeng P, Liang W, et al. FTY720 attenuates angiotensin II-induced podocyte damage via inhibiting inflammatory cytokines. Mediators Inflamm. 2017;2017:3701385.

67. Balasa RI, Simu M, Voidazan S, et al. Natalizumab changes the peripheral profile of the Th17 panel in MS patients: new mechanisms of action. CNS Neurol Disord Drug Targets. 2017;16:1018-1026.

68. Bar-Or A, Pachner A, Menguy-Vacheron F, Kaplan J, Wiendl H. Teriflunomide and its mechanism of action in multiple sclerosis. Drugs. 2014;74:659-674.

69. Yildiz M, Tettenborn B, Putzki N. Multiple sclerosis-associated fatigue during disease-modifying treatment with natalizumab, interferon-beta and glatiramer acetate. Eur Neurol. 2011;65:231-232.

70. He D, Guo R, Zhang F, Zhang C, Dong S, Zhou H. Rituximab for relapsing-remitting multiple sclerosis. Cochrane Database Syst Rev. 2013;12:CD009130.

71. Hoepner R, Faissner S, Salmen A, Gold R, Chan A. Efficacy and side effects of natalizumab therapy in patients with multiple sclerosis. J Cent Nerv Syst Dis. 2014;6:41-49.

72. Stephenson JS, Kern DM, Agarwal SS, et al. Impact of natalizumab on patient-reported outcomes in multiple sclerosis: a longitudinal study. Health Qual Life Outcomes. 2012;10:155-164.

73. Svenningsson A, Falk E, Celius EG, et al. Natalizumab treatment reduces fatigue in multiple sclerosis: results from the TYNERGY trial - a study in the real life setting. PLoS One. 2013;8:e58643.

74. Iaffaldano $P$, Viterbo RG, Paolicelli D, et al. Impact of natalizumab on cognitive performances and fatigue in relapsing multiple sclerosis: a prospective, open-label, two years observational study. PLoS One. 2012;7:e35843.

75. Masingue M, Debs R, Maillart E, et al. Fatigue evaluation in fingolimod treated patients: an observational study. Mult Scler Relat Disord. 2017;14:8-11.

76. Shuster EA. Hormonal influences in multiple sclerosis. Curr Top Microbiol Immunol. 2008;318:267-311.

77. Pelfrey CM, Cotleur AC, Lee JC, Rudick RA. Sex differences in cytokine responses to myelin peptides in multiple sclerosis. J Neuroimmunol. 2002;130:211-223.

78. Segal BM, Cohen JA, Antel J. Americas Committee for Treatment and Research in Multiple Sclerosis Forum 2017: environmental factors, genetics, and epigenetics in MS susceptibility and clinical course. Mult Scler. 2018;24:4-5.

79. Chalah MA, Ayache SS. Psychiatric event in multiple sclerosis: could it be the tip of the iceberg? Rev Bras Psiquiatr. 2017;39:365-368.

80. Chalah MA, Ayache SS. Alexithymia in multiple sclerosis: a systematic review of literature. Neuropsychologia. 2017;104:31-47.

81. Hughes AJ, Dunn KM, Chaffee T. Sleep disturbance and cognitive dysfunction in multiple sclerosis: a systematic review. Curr Neurol Neurosci Rep. 2018;18:2. 


\section{Publish your work in this journal}

The Journal of Inflammation Research is an international, peer-reviewed open access journal that welcomes laboratory and clinical findings on the molecular basis, cell biology and pharmacology of inflammation including original research, reviews, symposium reports, hypothesis formation and commentaries on: acute/chronic inflammation; mediators of inflammation; cellular processes; molecular mechanisms; pharmacology and novel anti-inflammatory drugs; clinical conditions involving inflammation. The manuscript management system is completely online and includes a very quick and fair peer-review system. Visit http://www.dove press.com/testimonials.php to read real quotes from published authors.

Submit your manuscript here: https://www.dovepress.com/journal-of-inflammation-research-journal 